\title{
Design and Analysis of Car Explosion-Proof Tire Safety Wheel Hub
}

\author{
Jie $\mathrm{Wu}^{\mathrm{a}}$, Yanbin Qi ${ }^{\mathrm{b}}$ and Yue Zhang ${ }^{\mathrm{c}}$ \\ School of Mechanical Engineering, Shenyang University, Liaoning 110044, China. \\ awujied85@163.com, b1650432270@ qq.com, '1852609778@@qq.com
}

\begin{abstract}
The wheel hub is a metal part which is in a car tire for supporting a tire and fixing the tire rim. It is loaded with the tire by the car. When the car is moving, interaction force by the wheel contact with the ground and drive the vehicle by the torque is transmitted to the hub. So, the strength of the hub is an important factor in vehicle safety. The main cause of car rollover because of the burst was analyzed in this paper. That is to maintain a traditional wheel main structure diameter the same as the original lager. Outer rim diameter increases to close to the tire diameter. Also introduced the new type of car explosion-proof tire safety hub from several aspects of functional and structural characteristics analyzed the feasibility and rationality of the design and illustrates its practicability and effectiveness. Through improvements on the traditional automobile wheel hub, solve the car flat tire out when high-speed facing the person and the vehicle's safety problems.
\end{abstract}

Keywords: Safety wheel hub; Car explosion-proof tire; Design and Analysis.

\section{Introduction}

The car have already spread to every family, the car driving safety is very important, it threatens the life of drivers and passengers. Especially cars under the condition of the high speed, often occur because of a flat tire and make the vehicle out of control, lead to a vicious traffic accidents such as collision, rollover, it seriously threatens the safety of drivers, passengers and vehicles. After blowout vehicles imbalances, the driver it is difficult to control the escape, ensuring safety. Speeding on the highway vehicles, in particular, once the front side of the blowout must cause the vehicle to the flat tire side tilt and overturned. According to the highway management departments, traffic on the highway, because of the bad shape (such as poor quality of tires, tire wear, steering failure, spontaneous combustion, etc.) caused by accident, caused by blowout accident rate in the first place. A flat tire blowout is not terrible, but caused the worst side of the vehicle, which can cause great loss and damage to personal property. Through improvements on the traditional automobile wheel hub, solve the car flat tire out when high-speed facing the person and the vehicle's safety problems.

\section{The cause of vehicle rollover}

For car, engine and transmission and so on mechanical transmission device front, body nearly two-thirds of the two front wheel weight on the car, the first two rounds of burden overweight, the work load for a long time. Especially when braking, the additional dynamic load step in car body center of gravity forward, the wheels and the ground pressure, friction is also increasing, easily to front wheel flat tire. Front wheel flat tire is one of the most dangerous, especially when a front wheel flat tire, in car body gravity, inertia force, braking force and additional dynamic pressure, is bound to cause the body to first flat tire side tilt, at this time can only rely on wheel roll over to prop up the body, wheel rolling on the ground, the driving resistance also increase. If the wheel diameter is smaller, the vehicle to the flat tire side Angle. Is in this under the action of multiple factors, the speed slow lead to vehicle side collision, fast speed will lead to the vehicle, a major accident to personal property.

The direct cause of vehicle rollover is a flat tire, but the root cause of vehicle rollover is tires and wheel technology design is not reasonable, is the diameter of the tire and the diameter of the wheel gap is too big! Vehicle this gap, the greater the flat tire, the more prone to excessive tilts and rolled over. Table 1 is the typical vehicle wheel edge distance with the ground survey data. 
Table 1 TheTypical Vehicle Wheel Edge Distance with the Ground Survey Data

\begin{tabular}{ccccc}
\hline Numble & type of motor vehicles & $\begin{array}{c}\text { Diameter of } \\
\text { wheels } \\
(\mathrm{mm})\end{array}$ & $\begin{array}{c}\text { Diameter of tire } \\
(\mathrm{mm})\end{array}$ & $\begin{array}{c}\text { Distance between the wheel edge } \\
\text { and ground(mm) }\end{array}$ \\
\hline 1 & Volkswagen Jetta & 390 & 590 & 100 \\
2 & Passat TS1 & 440 & 660 & 110 \\
3 & Roewe 750 & 470 & 650 & 90 \\
4 & Audi Q5 & 490 & 740 & 125 \\
5 & LAND ROVER & 460 & 720 & 130 \\
6 & BYD & 480 & 710 & 115 \\
\hline
\end{tabular}

Can be seen from the data in table 1 most car tire and wheel diameter difference is bigger, wheel edge of the distance from ground is mostly in more than $100 \mathrm{~mm}$, the distance, the greater the vehicles, the greater the slope after puncture rollover the greater the danger.

Now, some car manufacturers try to keep the tire diameter is constant, increasing the inner diameter of the tire and wheel diameter, the purpose is to reduce the separation between wheel and road surface, but doing so just ease, sparked puncture cannot fundamentally solve the safety hidden trouble. It also can reduce rubber tires, wheel chamber decreases, and the wheels reduce shock absorption shock absorption ability. Therefore, design a new type of car explosion-proof safety hub, prevent and eliminate the traffic safety accident due to puncture is the top priority.

\section{The design of the wheel hub}

Now use of automobile wheel hub, on both sides of the flange is such as diameter, and the diameter of the tire is bigger than wheel rim diameter. In order to overcome the insufficiency of traditional automobile wheel hub and safe hidden trouble, based on the principle of compatible with existing, simple and practical, innovative design scheme of new type of car safety wheel is shown in figure 1.

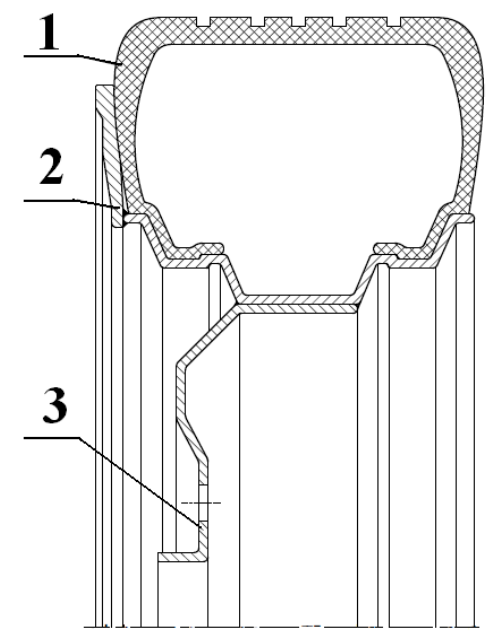

1-Tire; 2-Strengthen rims; 3-Wheel hub

Fig. 1 The assembly drawing of Car explosion-proof tire safety wheel hub

As shown in figure 1 is the driving wheels of the car side car explosion-proof tire safety wheel hub assembly diagram. This design is mainly composed of wheel strengthen the rims of tire.

Two flange hub, one is the wheel rim, another is the wheel rim, the diameter of the wheel rim outside is greater than the wheel rim, the diameter of the wheel rim outside is smaller than the diameter of the rubber tire around $100 \mathrm{~mm}$. Wheel rim inside diameter is as large as the diameter of the original traditional wheel rim. Wheel hub 1 still is made by high quality carbon steel or high strength aluminum alloy.

This design is for wheel hub of two wheel rim diameter ranging from design; inner rim is as large as traditional wheel diameter, outer rim increases to around $100 \mathrm{~mm}$ smaller than the diameter of a tire. 
Two flange each have each use, the dismantling of the tire from the inner rim of; the role of the outer rim is when blowout, rapid replacement tires bore the burden of supporting the vehicle. Even if the outside wheel vehicles would also be tilted at work, but the Angle is less than before improvement, not enough to cause the vehicle rollover.

New design of wheel body is still produced by high quality carbon steel or high strength aluminum alloy; outer rim must be properly wall thickening, in order to meet the bear after flat tire pressure to the body weight and dynamic load.

This design also maintain the basic structure of traditional automobile wheel hub style and size is changeless, rubber tire structure form and size also do not need to make any changes, according to the structure design of car wheel hub, which can both retain the advantages of traditional wheel and tire wear \&erosive way; A flat tire and can ensure the vehicle to avoid due to unbalanced support large tilt, effectively prevent the vehicle, to prevent and eliminate fundamentally for automobile traffic accident, which caused by the flat tire for cars, drivers and passengers with sufficient security.

\section{The working principle of the wheel hub}

Installing a wheel, wheel hub of the outer rim must be installed on the outer edge of the body, so assembly, during a blowout, relative to the outer rim of car support width, the largest vehicle tilting prevention security is the best.

New type of car safety wheel, rubber tire still flange installation. Play a key role in the safety of the outer rim. A blowout occurs, carrying auto part weight, support vehicles avoiding bodywork tilt, ensure vehicle, not maintain vehicle safety forward until the stop.

When the tire shortage on gas, outer rim contact with the road surface and rolling on the road, at this time of rigid vibration and mechanical noise can make the driver feel tire abnormal, parking, quickly found the problem as early as possible, eliminate hidden dangers. Three is to protect the tire. In the serious lack of gas or a flat tire, traditional wheel hub inner and outer rim will at the same time until the rolling tire destroy; For the new type safety hub, due to the wheel rim is lower than the outer rim, lack of the deformation of tire is bound to fall inward flange side of the gas, the outer rim will replace support car tires, so as to protect the tire from crushing destruction; In addition, as a car travels too near the road, the outer rim also can protect the tire would not be hurt by the road stone or sharp objects.

Does not appear when the car moving, tire blowout or lack of the abnormal phenomenon such as gas, a new type of car safety tire wheel only support vehicles and protection function, outer rim may only stay in working state. In the event of a blowout or tire serious lack of gas, outer rim immediately into the work state, protect. If there is a large potholes in the road, or in case of large stones hard road, outer rim may be short-term contact with the ground, even so, will only create a short vibration and discomfort, the vehicle will not damage the vehicle, also won't produce the vehicle's safety accident, it will remind the driver slowed down.

In addition to increasing outer rim, the structure of the new type of car safety wheel and other size can be consistent with the traditional, remains the same, the structure of rubber tires also do not make any changes to the style and size. Therefore, when need to repair or replace rubber tire, just from this side of the wheel rim in tire will be removed, tire and wheel wear \&erosive traditional operation method are exactly the same with the past. In addition, the installation of the wheel assembly and car body operation mode with the traditional also remain the same.

With Audi Q5 and Passat TS1 two cars, for example, two car wheel tracks and wheelbase and improvement of front wheel rim from the distance of the ground parameters shown in table 2 .

If the two car wheel rim and tire improved the difference as the $80 \mathrm{~mm}$ diameter, so, two car outer rim are $40 \mathrm{~mm}$ off the ground, can calculate the wheel rim improve bodywork tilt situation before and after the flat tire, see table 3. 
Table 2 Two Car comparing

\begin{tabular}{cccc}
\hline $\begin{array}{c}\text { type of motor } \\
\text { vehicles }\end{array}$ & $\begin{array}{c}\text { Distance of the wheel } \\
(\mathrm{mm})\end{array}$ & $\begin{array}{c}\text { Distance of the axis } \\
(\mathrm{mm})\end{array}$ & $\begin{array}{c}\text { Distance between the wheel edge } \\
\text { and ground }(\mathrm{mm})\end{array}$ \\
\hline Passat TS1 & 1500 & 2850 & 110 \\
Audi Q5 & 1600 & 2830 & 125 \\
\hline
\end{tabular}

Table 3 Two Car Angle comparing

\begin{tabular}{cccc}
\hline type of motor vehicles & $\begin{array}{c}\text { The improved outer rim distance } \\
\text { off the ground } \\
(\mathrm{mm})\end{array}$ & Improved Angle before & Improved Angle after \\
\hline Passat TS1 & 40 & $4.9^{\circ}$ & $1.8^{\circ}$ \\
Audi Q5 & 40 & $5.5^{\circ}$ & $1.5^{\circ}$ \\
\hline
\end{tabular}

Data from table 3, according to the new wheel running two cars, when a single front wheel tire blowout, on one side of the car body to puncture Angle, Passat TS1 nearly three times smaller than the traditional wheel; The audi Q5 small nearly four times. And, two kinds of vehicle driving safety is better than the original increase the degree of the same. Therefore, the new type of car safety hub for security play an important role to improve the car.

\section{Conclusion}

To sum up, this article design a new type of car explosion-proof tire safety wheel hub is feasible, effective, to prevent and eliminate for the car driving safety hidden danger of puncture and play a positive role in promoting. This article is creative, as a principle of design, but it is a good start, is of great practical value. To deepen the ideas of the design, improvement, eventually become reality effectively, to do intensive research, there are many technical problems need to solve, must do a lot of experiment.

\section{References}

[1] Sun Li, The design method of Car wheel hub, decoration, 2011(6) 110-11.

[2] Sun Qun, The kind of aluminum alloy wheel hub design, Mechanical design and manufacturing, 2013(6): 54-57.

[3] Cheng Gang, the Safe method with Highway traffic Science and technology innovation 2012 (1):48-49. 